\title{
Asymptomatic carriage of Clostridium difficile in patients with cystic fibrosis
}

\author{
S L PEACH, * S P BORRIELLO, $\dagger$ H GAYA,* F E BARCLAY, $\dagger$ A R WELCH $\dagger$ \\ From the *Department of Microbiology, The London Chest Hospital, London and the $†$ Division of \\ Communicable Diseases, Clinical Research Centre, Harrow, Middlesex
}

SUMmary Faecal samples from 37 patients with cystic fibrosis and 40 control patients at the Brompton Hospital and the London Chest Hospital were examined for the presence of Clostridium difficile. The organism was isolated from $2(17 \%)$ of control patients who were receiving antibiotics and from one (3.6\%) of control patients who had no antimicrobial treatment. Thirty two per cent of the patients with cystic fibrosis excreted $C$ difficile, though none of them had diarrhoea. Two of the three isolates from control patients and nine of the 12 isolates from patients with cystic fibrosis produced toxin B (cytotoxin) in vitro. Toxin B was present in the stools of one of the control patients and three of the patients with cystic fibrosis; toxin A (enterotoxin) was not detected in the faeces of the patients with cystic fibrosis. Two cytotoxigenic strains of Cdifficile isolated from patients with cystic fibrosis were examined in hamsters; both were virulent, and the animals died.

Clostridium difficile is the primary cause of most cases of pseudomembranous colitis as well as many cases of diarrhoea associated with antibiotics. ${ }^{1}$ A combination of antibiotics, which may disrupt the normal gut flora and make the patient susceptible to infection with $C$ difficile, and a hospital stay, which would increase the risk of exposure to this organism, would result in an increased risk of $C$ difficile mediated gastrointestinal disease. Patients often exposed to both of these risk factors are those with cystic fibrosis. These patients receive almost continual antimicrobial prophylaxis and are often inpatients, although symptoms of diarrhoea associated with antibiotics are rare-despite recent work that shows a relatively high carriage rate of $C$ difficile. ${ }^{2-4}$

The purpose of this study was to confirm this apparent high carriage rate both in inpatients and outpatients with cystic fibrosis at two different hospitals in London, England; to compare the carriage rate with that of other subjects with respiratory problems who were taking antibiotics; and further, to try to determine why the carriage of Cdifficile in these patients is asymptomatic.

Accepted for publication 22 April 1986

\section{Material and methods}

PATIENTS AND SPECIMENS

Faecal samples were obtained from 77 patients at the London Chest Hospital (LCH) and the Brompton Hospital, London (BH). Thirty seven of these patients had cystic fibrosis (mean age 19.1 years, range 6-32 years). Eight of the patients with cystic fibrosis were inpatients at $\mathrm{LCH}, 10$ were inpatients at $\mathrm{BH}$, and 19 were outpatients at $\mathrm{BH}$; all but two were receiving antibiotics, seven receiving only nebulised antibiotics; and most were receiving treatment for pancreatic insufficiency, which was well controlled in all cases.

The control group consisted of 35 inpatients at LCH and five inpatients at BH (mean age 56 years, range 27-78 years), who were suffering from respiratory tract diseases unrelated to cystic fibrosis. These included emphysema, asthma, chronic obstructive airways disease, and carcinoma. Twelve of these patients were receiving antibiotics. None of the patients had diarrhoea or other gastrointestinal illness at the time of study.

Faecal samples (about $10 \mathrm{~g}$ ) were sent directly to the diagnostic laboratories of $\mathrm{LCH}$ from the wards, or by post from the patients' homes, in sterile plastic universal bottles. They were stored undiluted at $-20^{\circ} \mathrm{C}$ for no more than one month before cultivation. 
ISOLATION AND IDENTIFICATION OF $C$ difficile About $0 \cdot 1 \mathrm{~g}$ of undiluted faeces was seeded directly on to selective agar. The medium was a modification of that described by George et $a l^{5}$ and consisted of Columbia agar base with the addition of $0.05 \% \mathrm{w} / \mathrm{v}$ cysteine hydrochloride, $0.03 \% \mathrm{w} / \mathrm{v}$ sodium formaldehyde sulphoxylate, $7 \% \mathrm{v} / \mathrm{v}$ defibrinated horse blood, and $500 \mathrm{mg} / \mathrm{l}$ of D-cycloserine (Sigma) and $20 \mathrm{mg} / \mathrm{l}$ of cefoxitin (Merck, Sharp, and Dohme) as selective agents. The medium was stored at room temperature in an anaerobic environment for 24 hours before use. Seeded plates were incubated at $37^{\circ} \mathrm{C}$ for 48 hours in anaerobe jars containing an anaerobic environment generated by a gas kit system (Oxoid, Basingstoke). Anaerobiosis was monitored by resazurin indicator strips (Oxide). Fresh catalyst (reactivated by heating at $160^{\circ} \mathrm{C}$ for two hours) was used in each anaerobe jar.

A similar sample of faeces $(0 \cdot 1 \mathrm{~g})$ was inoculated into Robertson's cooked meat medium (Southern Group Laboratories), which was incubated aerobically at $37^{\circ} \mathrm{C}$ for 48 hours and then subcultured on to the selective agar, incubated as described above.

After incubation the primary isolation agar plates were examined for colonies typical of $C$ difficile, and a semiquantitative estimate of the amount of growth was recorded: + for growth at original inoculation site only; ++ for growth also in primary streaks; +++ for growth also in secondary streaks. When Cdifficile was recovered only after enrichment in Robertson's cooked meat medium growth was recorded as $\mathrm{E}$ positive.

Colonies typical of $C$ difficile were presumptively identified by their characteristic pale green fluorescence under long wave $(360 \mathrm{~nm})$ ultraviolet light, ${ }^{56}$ their typical cellular appearance in a Gram stained preparation after growth on Columbia blood agar, $^{6}$ and the smell of paracresol. Full identification was confirmed by conventional techniques including gas-liquid chromatography, as described in detail elsewhere. ${ }^{6}$

\section{STORAGE OF ISOLATES}

Cultures of $C$ difficile were stored at room temperature in Robertson's cooked meat medium.

TESTS FOR TOXIGENIC STATUS OF ISOLATES Isolates of $C$ difficile were tested for their ability to produce toxin B (cytotoxin) in vitro by screening for cytopathic effects in African green monkey kidney (Vero) cells by the "conventional tube method," as described elsewhere. ${ }^{7}$ The toxin B titre was also determined in all positive stools. Stools from patients with cystic fibrosis, which were positive for toxin $\mathbf{B}$, were also screened for the presence of toxin $A$ (enterotoxin) by an ELISA technique. ${ }^{8}$

\section{PATHOGENICITY OF Cdifficile ISOLATES IN}

\section{HAMSTERS}

Two of the cytotoxigenic isolates of $C$ difficile that produced toxin $B$ in vivo were investigated for their ability to cause disease in hamsters. Each strain was tested in a pair of animals. The methods used have been described in detail elsewhere. ${ }^{910}$ Briefly, hamsters pretreated with clindamycin were housed individually in sterile isolator cages and given $0.5 \mathrm{ml}$ of a washed suspension of $C$ difficile containing $10^{4}$ organisms $/ \mathrm{ml}$. One strain was given five days and the other nine days after clindamycin. At death faecal material was analysed for the presence of $C$ difficile and toxin $\mathbf{B}$.

\section{GROWTH IN FAECAL EMULSIONS}

The stools from six patients with cystic fibrosis who did not harbour $C$ difficile were screened for their ability to support the in vitro growth of a toxigenic strain of $C$ difficile (strain B-1), using a recently developed in vitro model of colonisation resistance, described in $\mathrm{O}$ detail elsewhere. ${ }^{11}$ Briefly, stools diluted 20-fold in sterile distilled water were seeded with an actively $\mathscr{D}$ growing culture of $C$ difficile, and growth and toxin $B$ production over 48 hours were monitored. Two of the faecal emulsions that were inhibitory were filter sterilised and the growth of $C$ difficile was monitored in the sterile filtrates to determine whether the inhibitio was due to antagonism exerted by the normal flora, is the case in healthy adults, or, due to other cell fres factors.

DETERMINATION OF FAECAL PH

Determinations of $\mathrm{pH}$ on sterile aqueous filtrates of 1/10 dilutions of faeces were done with a $\mathrm{pH}$ meter (model 38B, Electronic Instruments Ltd, Richmond, Surrey, England).

\section{Results}

ISOLA TION OF C difficile

$C$ difficile was isolated from two of the twelve control patients $(17 \%)$ who had received antibiotics. Both patients had been treated with cephalosporins (table 1). In contrast, $C$ difficile was isolated from only one of the 28 control patients $(3.6 \%)$ who had had no antibiotic treatment. In total, three of $40(7.5 \%)$ control patients carried $C$ difficile in their stools. All three were inpatients on a single ward at $\mathrm{LCH}$. Two of $S$ these isolates produced toxin B in vitro, and toxin B was detected in the stools of one of the patients carrying $C$ difficile (table 1).

Twelve $(32 \%)$ of the patients with cystic fibrosis carried $C$ difficile in their stools. There was an appre- $\frac{\widetilde{D}}{\Phi}$ ciable difference in the isolation rate of $C$ difficile $\stackrel{\mathscr{S}}{?}$ between patients at $\mathrm{LCH}(62 \cdot 5 \%)$ and those at $\mathrm{BH}$ 
Table 1 Details of control patients carrying $C$ difficile

\begin{tabular}{lllllll}
\hline Age & Sex & $\begin{array}{l}\text { Cytotoxigenic status } \\
\text { of Cdifficile }\end{array}$ & $\begin{array}{l}\text { Toxin } B \\
\text { in stool }\end{array}$ & Faecal pH & Antibiotic & Diagnosis \\
\hline 68 & F & Positive & Positive & & $\begin{array}{l}\text { None } \\
\text { (prednisolone) }\end{array}$ & Lung cancer \\
64 & M & $\begin{array}{l}\text { Negative } \\
\text { Positive }\end{array}$ & $\begin{array}{l}\text { Negative } \\
\text { Negative }\end{array}$ & 6.8 & $\begin{array}{l}\text { Cefuroxime } \\
\text { Ceftazidime }\end{array}$ & $\begin{array}{l}\text { Lung cancer } \\
\text { Bronchiectasis }\end{array}$ \\
\hline
\end{tabular}

(24\%). All of those with cystic fibrosis from whom $C$ difficile was isolated had received antibiotics by mouth or injection (table 2), giving a carriage rate of $43 \%$ among those taking antibiotics by these routes. The organism was not isolated from any of those patients with cystic fibrosis who had not received antibiotics or received only nebulised antibiotics. All the patients with cystic fibrosis carrying $C$ difficile at LCH were inpatients on the same ward, which was also the ward on which the control patients with $C$ difficile were nursed. Five of the patients from $\mathrm{BH}$ with cystic fibrosis who carried $C$ difficile were outpatients and two were inpatients on separate wards. In one of the patients with cystic fibrosis $C$ difficile was isolated from an enrichment culture but not from the direct faecal culture. All but one of the patients carrying Cdifficile were receiving either a cephalosporin or a penicillin (tables 1 and 2). In addition, many of the patients, were receiving an aminoglycoside. Similar treatment was received by some of the patients from whom Cdifficile was not isolated (table 3).

Table 2 Details of patients with cystic fibrosis carrying $C$ difficile

\section{Cdifficile AND FAECAL TOXICITIES}

Two of the three isolates of $C$ difficile from control patients produced toxin $B$ in vitro, but toxin B was only detected in one of these two stools (table 1). Nine of the 12 isolates of $C$ difficile from the patients with cystic fibrosis were cytotoxigenic, and toxin B was detected in three of these stools at titres of $1 / 1024$, 1/4096, and 1/16384 (table 2). These three stools, however, did not contain detectable amounts of toxin A.

\section{FAECAL PH}

Faecal $\mathrm{pH}$ values were determined for the one control patient and the five with cystic fibrosis who had no toxin B in the faeces but who were excreting cytotoxigenic $C$ difficile and for two of the patients with cystic fibrosis who had toxin B in their stools. The purpose of these measurements was to determine if the absence of faecal toxin $B$ in patients colonised with toxigenic $C$ difficile was due to $\mathrm{pH}$ mediated toxin degradation. Tables 1 and 2 show the results. None of the faeces was sufficiently acidic to degrade toxin $\mathrm{B}$.

\begin{tabular}{|c|c|c|c|c|c|c|c|c|c|}
\hline \multirow[b]{2}{*}{ Age } & \multirow[b]{2}{*}{$\operatorname{Sex}$} & \multirow{2}{*}{$\begin{array}{l}\text { Cytotoxigenic } \\
\text { status of } \\
C \text { difficile }\end{array}$} & \multirow{2}{*}{$\begin{array}{l}\text { Toxin B } \\
\text { titre in } \\
\text { stool }\end{array}$} & \multirow{2}{*}{$\begin{array}{l}\text { Relative } \\
\text { concentration of } \\
\text { Cdifficile } \\
\text { in stool }\end{array}$} & \multirow[b]{2}{*}{ Faecal pH } & \multirow[b]{2}{*}{ Hospital } & \multirow[b]{2}{*}{$\begin{array}{l}\text { In/out } \\
\text { patient }\end{array}$} & \multicolumn{2}{|l|}{ Antibiotics } \\
\hline & & & & & & & & $\begin{array}{l}\text { By mouth or } \\
\text { injection }\end{array}$ & Nebulised \\
\hline 18 & $\mathbf{M}$ & Positive & $1 / 4096$ & $2+$ & 5.97 & \multirow{7}{*}{$\begin{array}{l}\text { London Chest } \\
\text { Hospital }\end{array}$} & In & Tobramycin & \multirow{7}{*}{$\begin{array}{l}\text { Tobramycin } \\
\text { Colistin } \\
\text { Ticarcillin } \\
\text { Piperacillin }\end{array}$} \\
\hline 16 & $\mathbf{M}$ & Negative & - & + & & & In & Tobramycin & \\
\hline 19 & $\mathbf{M}$ & Positive & $1 / 16384$ & $3+$ & $6 \cdot 7$ & & In & $\begin{array}{l}\text { Tobramycin } \\
\text { Azlocillin }\end{array}$ & \\
\hline 23 & $\mathbf{M}$ & Negative & - & $2+$ & & & In & $\begin{array}{l}\text { Tobramycin } \\
\text { Azlocillin }\end{array}$ & \\
\hline 21 & $\mathbf{F}$ & Negative & - & $3+$ & & & Out & Flucloxacillin & \\
\hline 15 & $\mathbf{F}$ & Positive & - & $3+$ & $5 \cdot 8$ & & Out & \multirow{4}{*}{$\begin{array}{l}\text { Ceftazidime } \\
\text { Tobramycin } \\
\text { Ticarcillin } \\
\text { Tobramycin } \\
\text { Flucloxacillin } \\
\text { Flucloxacillin }\end{array}$} & \\
\hline 21 & $\mathbf{F}$ & Positive & - & + & $6 \cdot 3$ & & Out & & \\
\hline 19 & $\mathbf{M}$ & Positive & - & E positive & $6 \cdot 0$ & \multirow[t]{2}{*}{$\begin{array}{l}\text { Brompton } \\
\text { Hospital }\end{array}$} & & & \multirow[t]{2}{*}{$\begin{array}{l}\text { Gentamicin } \\
\text { Carbenicillin }\end{array}$} \\
\hline 17 & $\mathbf{M}$ & Positive & - & + & 5.9 & & Out & & \\
\hline 16 & $\mathbf{M}$ & Positive & $1 / 1024$ & + & & & In & \multirow{3}{*}{$\begin{array}{l}\text { Ticarcillin } \\
\text { Gentamicin } \\
\text { Ceftazidime } \\
\text { Tobramycin } \\
\text { Flucloxacillin }\end{array}$} & \\
\hline 26 & $\mathbf{M}$ & Positive & - & + & $6 \cdot 0$ & & In & & \\
\hline 17 & $\mathbf{M}$ & Positive & - & $2+$ & J & & Out & & \\
\hline
\end{tabular}


Table 3 Systemic antibiotic treatment of patients who did not carry $C$ difficile

\begin{tabular}{|c|c|c|c|}
\hline & No of patients & Hospital & Antibiotics \\
\hline Controls & 10 & $\begin{array}{l}\text { London Chest } \\
\text { Hospital }\end{array}$ & $\begin{array}{l}\text { Erythromycin }(n=4) \text {, cefuroxime, ceftazidime, } \\
\text { tetracycline, co-trimoxazole, } \\
\text { gentamicin + ampicillin, not known }\end{array}$ \\
\hline \multirow[t]{2}{*}{$\begin{array}{l}\text { Patients with } \\
\text { cystic fibrosis }\end{array}$} & 4 & $\begin{array}{l}\text { London Chest } \\
\text { Hospital }\end{array}$ & $\begin{array}{l}\text { Ceftazidime }(n=2) \text {, ceftazidime }+ \text { flucloxacillin, } \\
\text { tobramycin }+ \text { azlocillin }\end{array}$ \\
\hline & 12 & Brompton Hospital & $\begin{array}{l}\text { Carbenicillin, flucloxacillin, } \\
\text { flucloxacillin + amoxycillin }(n=2) \\
\text { flucloxacillin + tetracycline, } \\
\text { gentamicin + ticarcillin, } \\
\text { gentamicin + ticarcillin + carbenicillin, } \\
\text { gentamicin + carbenicillin, } \\
\text { gentamicin + ceftazidime, } \\
\text { netilimicin + azlocillin }(n=2) \\
\text { erythromycin + ceftazidime }\end{array}$ \\
\hline
\end{tabular}

Table 4 Survival of $C$ difficile over 48 hours in faecal emulsions prepared from stools of patients with cystic fibrosis not carrying organism

\begin{tabular}{lllll}
\hline $\begin{array}{l}\text { Patient } \\
\text { Age }\end{array}$ & $\begin{array}{l}\text { Change in numbers } \\
\text { of C difficile }\end{array}$ & $\begin{array}{l}\text { Production of } \\
\text { toxin } B(\text { titre })\end{array}$ & Faecal pH & Antibiotics \\
\hline 18 & 10 fold increase & Yes $(16384)$ & & Ceftazidime \\
40 & 10 fold decrease & No & Ticarcillin, gentamicin \\
21 & 10 fold decrease & Yes (256) & Tobramycin, azlocillin \\
6 & $10^{2}$ fold decrease & No & Azlocillin, netilimicin \\
20 & $10^{6}$ fold decrease & No & $7 \cdot 1$ & Ethambuttol, rifampicin, erythromycin \\
23 & $10^{6}$ fold decrease & No & & Gentamicin, carbenicillin \\
\hline
\end{tabular}

*Sterile faecal emulsion filtrate inhibitory to the same degree.

GROWTH OF C difficile IN FAECAL EMULSIONS

Growth of $C$ difficile in faecal emulsions prepared from patients with cystic fibrosis who were not excreting the organism was monitored to determine the degree and nature of colonisation resistance (table 4). $C$ difficile grew in the faecal emulsion from one of these patients and produced toxin $B$ to a titre of $1 / 16384$. Three of the faecal emulsions were mildly inhibitory, resulting in a decrease in the numbers of $C$ difficile of between 10 and 100 -fold. In all cases the total number of vegetative cells of $C$ difficile was greater than the number of spores present, showing that survival was not simply a function of presence of spores. In one of these three cases a small amount of toxin B was produced (titre $1 / 256$ ), implying that at some stage the cells were also metabolically active. In two cases the faecal emulsions were extremely inhibitory resulting in a $10^{6}$-fold decrease in total numbers of $C$ difficile. In the one case analysed the sterile filtrate was equally as inhibitory. This inhibition was not due to an acidic $\mathrm{pH}$ as the stool had a $\mathrm{pH}$ value of $7 \cdot 1$.

\section{PATHOGENICITY OF $C$ difficile IN HAMSTERS}

Both strains of $C$ difficile tested were pathogenic in hamsters. The strain given five days after clindamycin had killed both animals within 24 hours, and the strain given nine days after clindamycin had killed both animals after 72 hours. Toxigenic $C$ difficile and free toxin B were found in the caecal contents at death in both cases.

\section{Discussion}

This study clearly shows a high asymptomatic carriage rate of toxigenic strains of $C$ difficile in patients with cystic fibrosis. In all, $32 \%$ of these patients carried $C$ difficile in their faeces and all of them were receiving antibiotics. Interestingly, none of the patients on nebulised antibiotics alone carried the organism. This carriage rate is similar to that of $31 \%$ observed by Wu et al ${ }^{2}$ but higher than that of $22 \%$ observed by Welkon et al. ${ }^{4}$ Analysis of the data provided by this and other workers shows that the increased rate of colonisation of patients with cystic fibrosis is, most likely, a consequence of the antibiotics that are often given with this disease as opposed to a direct result of the underlying disease itself. We found that none of the patients with cystic fibrosis who were not taking antibiotics or only nebulised antibiotics carried $C$ difficile compared with $43 \%$ of those receiving antibiotics by mouth or injection; and $\mathrm{Wu} e \mathrm{al}^{2}$ failed to isolate Cdifficile from any of their patients with cystic fibrosis who were not receiving antibiotics. Unfortunately, it is impossible to determine how many of those patients who were not taking antibiotics in the study by Welkon et $a l^{4}$ carried Cdifficile. As $92 \%$ of them had had anti- 
biotics during the previous six months and only one subject who carried $C$ difficile had not received antibiotics, it is safe to assume that the carriage of C difficile in patients with cystic fibrosis in their study was also clearly associated with antibiotics.

It is valid, therefore, to compare the carriage rate of $C$ difficile in patients with cystic fibrosis, who are receiving antibiotics in addition to or other than in the nebulised form and who do not have diarrhoea, with that seen in patients with other disorders who are receiving antibiotics. Our carriage rate of $43 \%$ in patients with cystic fibrosis receiving antibiotics (other than just nebulised antibiotics) and values of $50 \%{ }^{2}$ and $22 \%{ }^{4}$ noted by others compare favourably with the asymptomatic carriage rates of $21 \%$ and $46 \%$ recorded by Viscidi et al ${ }^{12}$ and George et al, ${ }^{13}$ respectively, and the $17 \%$ seen in this study for other patients receiving antibiotics. The range of colonisation rates seen is probably a reflection of differences in the degree of exposure to $C$ difficile at different centres, as well as differences in the sample sizes examined, and it is not dissimilar to the large differences in colonisation rates seen in neonates, ${ }^{14} \mathrm{a}$ group susceptible to colonisation.

The higher rate of carriage in the patients with cystic fibrosis-compared with that of controls seen in our study-could be a reflection of the longer period of hospital stay (a mean of 12.8 days compared with 8.9 days) but it more probably reflects the increased number of times that patients with cystic fibrosis are admitted.

Stools from patients with cystic fibrosis receiving antibiotics but who were not colonised with $C$ difficile were analysed for their ability to inhibit the growth of C difficile in vitro showing that the faecal flora was, in general, non-inhibitory to $C$ difficile. There were some cases in which the faecal emulsion was grossly inhibitory, but this inhibition was also present in the sterile filtrate of the one faecal emulsion in which sufficient material was available for study, implying that the inhibition was unrelated to the presence of viable bacteria. This inhibition was not due to $\mathrm{pH}$ and was most likely due to inhibitory titres of antibiotic present in the gut. The in vitro findings in this group are very similar to those for adults without diarrhoea, receiving antibiotics, and who do not have cystic fibrosis. ${ }^{11}$ In contrast, faecal emulsions prepared from the stools of healthy adults inhibited the growth of $C$ difficile, though sterile filtrates did not, highlighting the importance of the presence of bacteria in inhibition. ${ }^{11}$

Although $75 \%$ of our isolates of $C$ difficile from patients with cystic fibrosis were cytotoxigenic, toxin $B$ was rarely detected in their faeces. The absence of the acid labile toxin $\mathrm{B}$ was not due to faecal $\mathrm{pH}$ as all of the stools analysed had a $\mathrm{pH}$-value greater than
$5 \cdot 5$, a value at which toxin $\mathrm{B}$ is stable at $37^{\circ} \mathrm{C} .{ }^{15}$ In the study by Wu et al ${ }^{2}$ only $27 \%$ of the $C$ difficile isolates were cytotoxigenic, and none of their patients had toxin B present in the faeces. In contrast, Welkon et al, ${ }^{4}$ found most of their isolates to be cytotoxigenic and toxin B present in $62 \%$ of their patients.

The lack of diarrhoea in the patients excreting toxin B may be due to the absence of toxin A. In support of this hypothesis is our study showing that the three patients with cystic fibrosis were asymptomatically excreting toxin B and had undetectable amounts of toxin A present. In infants, however, it is possible to have asymptomatic carriage of $C$ difficile, even with high titres of both toxins $A$ and $B$ in the faeces ${ }^{1617}$ : a similar situation could, therefore, exist in patients with cystic fibrosis. Asymptomatic carriage of toxigenic $C$ difficile in any group is difficult to explain. The lack of toxin production in vivo explains some cases, but why the environmental conditions are not conducive to toxin production in these cases remains unexplained, as do the reasons why, in our work, only one toxin was detected in the faeces. Although this could be a reflection of the differing sensitivities of the toxin detection systems used, the one for detection of toxin B being the most sensitive, there is evidence that available nutrients can determine the relative amounts of the two toxins produced. ${ }^{18}$

The fact that specific mucosal receptors for the toxins may be absent in patients with cystic fibrosis must also be considered. Despite the fact that it has recently been shown that not all toxigenic strains of C difficile are equally virulent ${ }^{19}$ this did not explain the asymptomatic carriage in our study, as the isolates tested were virulent in hamsters. In some patients there might have been sufficient concentrations of antibiotics to inhibit full expression of virulence. Whatever the reasons for the observation of asymptomatic carriage, it is evident that the environment of the gastrointestinal tract inhibits full expression of virulence.

Finally, it is now evident that patients with cystic fibrosis should be recognised as a possible reservoir of infection and that they represent a cross infection risk, especially as they are often nursed in large medical wards.

We thank the patients and nursing staff in this study and consultant physicians Dr DM Geddes, Dr SJ Steel, Dr J Warner, and Dr J Batten. We also thank Dr S Haslam for faecal enterotoxin analyses.

\section{References}

1 Borriello SP. Antibiotic-associated diarrhoea and colitis: the role of Clostridium difficile in gastrointestinal disorders. Boston: Martinus Nijhoff, 1984.

2 Wu TC, McCarthy VP, Gill VJ. Isolation rate and toxigenic 
potential of Clostridium difficile isolates from patients with cystic fibrosis. J Infect Dis 1983;148:176.

3 Peach S, Borriello SP, Gaya H. Carriage of Clostridium difficile in patients with cystic fibrosis and control group. J Med Microbiol 1984;18:v.

4 Welkon CJ, Long SS, Thompson CM, Gilligan PH. Clostridium difficile in patients with cystic fibrosis. Am J Dis Child 1985;139:805-8.

5 George WL, Sutter VL, Citron D, Finegold SM. Selective and differential medium for isolation of Clostridium difficile. J Clin Microbiol 1979;9:214-9.

6 Borriello SP, Honour P. Simplified procedure for the routine isolation of Clostridium difficile from faeces. J Clin Pathol 1981;34:1124-7.

7 Larson HE, Price AB. Pseudomembranous colitis: presence of clostridial toxin. Lancet 1977;ii:1312-4.

8 Redmond SC, Ketley JM, Mitchell TJ, Stephen J, Burdon DW, Candy DCA. Detection of Clostridium difficile enterotoxin (toxin A) by ELISA and other techniques. In: Collins $\mathrm{CH}$, Grange JM, eds. Isolation and identification of organisms of medical and veterinary importance. London: Academic Press, 1985.

9 Larson HE, Price AB, Borriello SP. Epidemiology of experimental enterocecitis due to Clostridium difficile. $J$ Infect Dis 1980;142:408-13.

10 Borriello SP, Barclay FE. Protection of hamsters against Clostridium difficile ileocaecitis by prior colonisation with nonpathogenic strains. J Med Microbiol 1985;19:339-50.

11 Borriello SP, Barclay FE. An in vitro model of colonisation resistance to Clostridium difficile infection. J Med Microbiol 1986;21:299-309.
12 Viscidi R, Willey S, Bartlett JG. Isolation rates and toxigenic potential of Clostridium difficile isolates from various patient populations. Gastroenterology 1981;81:5-9.

13 George WL, Rolfe RD, Finegold SM. Clostridium difficile and its cytotoxin in feces of patients with antimicrobial agentassociated diarrhoea and miscellaneous conditions. J Clin Microbiol 1982;15:1049-53.

14 Larson HE, Barclay FE, Honour P, Hill ID. Epidemiology of Clostridium difficile in infants. $J$ Infect Dis 1982;146:727-33.

15 Barclay FE. Colonization resistance of the digestive tract with respect to infection with Clostridium difficile. London: Institute of Medical Laboratory Sciences, (Thesis). 1985:156.

16 Borriello SP. Clostridium difficile and its toxin in the gastrointestinal tract in health and disease. Research and Clinical Forums 1979;1:33-5.

17 Libby JM, Donta ST, Wilkins TD. Clostridium difficile toxin A in infants. $J$ Infect Dis 1983;146:723.

18 Haslam SC, Ketley JM, Mitchell TJ, Stephen J, Burdon DW, Candy DCA. Growth and production of toxins A and B by Clostridium difficile in complex and defined media. $J$ Med Microbiol 1986;21:293-7.

19 Borriello SP, Ketley JM, Mitchell TJ, et al. Clostridium difficile-an analysis of putative determinants of virulence in the hamster model of antibiotic-associated colitis. $\mathrm{J} \mathrm{Med}$ Microbiol (in press).

Requests for reprints to: Dr SP Borriello, Division of Communicable Diseases, Clinical Research Centre, Watford Road, Harrow, Middlesex HA1 3UJ, England. 